\section{B A Institute of \\ YK Business Administration \\ 六下 \\ Karachi \\ Leadership and Ideas for Tomorrow}

Business Review

Volume 1 Issue 1 July - December 2006

7-1-2006

\title{
Random walk tests for KSE-100 index: Evidence and implications
}

Abdul Rashid

Institute of Business Management, Karachi, Pakistan

Follow this and additional works at: https://ir.iba.edu.pk/businessreview

Part of the Economics Commons

c) (i)

This work is licensed under a Creative Commons Attribution 4.0 International License.

\section{Recommended Citation}

Rashid, A. (2006). Random walk tests for KSE-100 index: Evidence and implications. Business Review, 1(1), 80-95. Retrieved from https://doi.org/10.54784/1990-6587.1096

This article is brought to you by iRepository for open access under the Creative Commons Attribution 4.0 License and is available at https://ir.iba.edu.pk/businessreview/vol1/iss1/8. For more information, please contact irepository@iba.edu.pk. 


\title{
ARTICLE \\ Random Walk Tests for KSE-100 Index: Evidence and Implications
}

\author{
Abdul Rashid
}

\begin{abstract}
The variance-ratio tests are used to test the random walk hypothesis for Pakistan's stock exchange. The evidence indicates that the stock prices generally do not follow random walk over the entire examined period. This piece of evidence is robust during the second sub-period. During the first sub-period, however, the stock prices do not behave non-randomly. The absence of a random walk is implying that profitable trading rules can be devised. The findings also show that the Karachi Stock Exchange falls back to normal after being dramatically affected by a shock.
\end{abstract}

\section{Introduction}

$\Gamma$ he issue whether stock prices follow random walk or not has been hotly debated 1 between finance practitioners and finance academics for a long time. The random walk hypothesis has also occupied an important place in modern finance. It is not, therefore, surprising that it has been widely tested resulting in a large empirical literature, which includes a small number of studies of the Pakistani equity market.

The random walk in stock prices implies that investors cannot foresee future prices using past price movements and earnings are completely a matter of luck. In contrast, if market does not follow random walk, there are sufficient profit opportunities to compensate investors for the cost of trading and information gathering. Thus, an investor can use available information about corresponding prices for predicting the future returns. Therefore, it is very important for investors, financial services providers, finance policy makers, and finance academics to know the behavior of stock markets. In addition, this analysis has very useful implications for both hedgers and speculators. Most hedgers do not employ continuous hedges. Instead, they select the times at which they want protection against adverse changes. Definitely, knowledge of market fluctuations can be used for effective hedging.

The core objective of this study is to investigate whether the Pakistani equity market behaves like a random walk vis-à-vis the market has a tendency to slip back/mean revert. To proceed with this, the study used variance-ratio tests developed by Lo and Mackinlay (1988). One main advantage of the variance-ratio tests is to report the average level of autocorrelations of increments. Since the variance-ratio minus one is approximately q-1 times the weighted sum of the first q-1 autocorrelation coefficients. Thus, they provide more robust results than any fundamental test of random walk. We find a negative autocorrelations of weekly increments in the KSE-100 index. According to Leroy (1973) and Locus (1978), however, the existence of autocorrelation in financial assets does not necessarily imply any market inefficiency. 
Positive autocorrelation of stock returns implies a slow adjustment of stock prices to new information (both insider \& outsider information). In contrast, negative autocorrelation of stock returns may be an indicator of departures from fundamental values. Moreover, the presence of negative serial correlation indicates that the risk factors involve in stock returns may vary overtime. One possible interpretation of the negative serial correlation in the return series is that market overreacts to "news", that is, following the first dramatic reaction to a shock, the market falls back to normal. This view is consistent with the permanent/transitory components model, which basically says that stock markets are driven by a fundamental component that reflects the efficient market prices and deviations from efficiency and this component reverts to something that is close to zero in the long-term (Risager (1998)).

The remainder of this paper is laid out as follows: Section 2 presents the literature survey. In this section, the study also reviews some empirical studied on Pakistani stock market. Section 3 demonstrates the data sources. The stock returns estimation, the random walk hypothesis and empirical methodology also discussed in this section. Section 4 presents the empirical results and final Section 5 summarizes and provides concluding remarks.

\section{Literature Review}

Samuelson (1965) was the first study that seriously applied the random walk hypothesis to financial markets. The title of his article: "Proof that Properly Anticipated Prices Fluctuate Randomly", itself provides a neatly summary of his findings. In an informationally efficient market price changes must be unpredictable if they are properly anticipated.

Laurence (1986) tested the random walk hypothesis for Singapore and Malaysia Stock Exchanges. Using closing prices for 16 stocks and 24 stocks respectively from Malaysia and Singapore, he found that the both stock exchanges are slightly far from random walks with 0.078 and 0.041 mean absolute serial coefficients respectively for Singapore and Malaysia. In addition, he reported that the distribution of equity returns is leptokurtic in both markets.

Lo \& Mackinlay have designed the variance-ratio test in 1988 to test the random walk hypothesis $(\mathrm{RWH})^{1}$. They compared variance estimators derived from data at various levels of frequencies for weekly stock returns in the New York Stock Exchange and American Stock Exchange for a period of over 32 years. They improved the variance ratio test by taking overlapping period and corrected the variances used in estimating the statistic for bias. They also proposed a heteroscedasticity-robust variance-ratio test

${ }^{1}$ Before Lo \& Mackinlay (1988), Campbell and Mankiw (1987), Fama and French (1987), and Huizinga (1987) have also estimated variance ratios in a variety of context; however, these studies do not provide any formal sampling theory as like Lo \& Mackinlay (1988). 
statistic to test the heteroscedastic random walk hypothesis. The analysis indicated that the random walk hypothesis strongly rejected for the entire sample period of 196285 and for all subperiods for a variety aggregate return indexes and size-sorted portfolios.

The study results also pointed out positive autocorrelation for weekly holding-period returns. The rejection of the random walk hypothesis by Lo \& Mackinlay (1988) was mainly due to the behavior of small stocks; however, they cannot be attributed entirely to the effects of infrequent trading or time-varying volatilities. In addition, they reported that the rejection of the random walk for weekly returns does not support the mean reversion hypothesis.

Kim and Startz (1991) analyzed the random walk process of stock prices by using weekly and monthly returns in five Pacific-Basin stock markets. They found that the mean reversion in stock prices was only a phenomenon of the pre-World War II period. Moreover, their results based on variance-ratio tests indicated that there is a positive serial correlation in stock returns.

Pan, Chiou, Hocking \& Rim (1991) used the variance-ratio test to examine the stock market behavior for five Asian countries including Japan, South Korea, Hong Kong, and Taiwan. They employed daily and weekly stock return for a five-year sample period. They rejected the null hypothesis of randomness for both daily and weekly returns for Singapore and Korea and accepted the null hypothesis in case of Japan. The null hypothesis for Hong Kong daily returns index and the Taiwan weekly returns index were also rejected. Furthermore, their results indicated that all the returns index based on the five market indices were positively auto correlated except for Japan.

Natividad and Santamaria (1997) tested the random walk hypothesis in the Spanish Stock Market. They used daily data on individual stocks from January 1980 to December 1992. Their results provide evidence against the random walk hypothesis. The results, based on simple correlation tests, show that there is a strong correlation with nonlinear dependence among daily returns. Furthermore, they used the variance-ratio test, which is robust to heteroscedasticity, and have urged that the rejection of the random walk hypothesis cannot be attributed completely to the effects of time varying volatilities. They concluded that the price changes can be potentially predictable at least in short time spans.

Risger (1998) investigated the mean reversion in Danish Stock Market. His study covers the period since World War I, from 1922 to 1995 with newly constructed Danish data set. The results based on variance-ratio test rejected the random walk hypothesis at 2-year horizons and accept the null hypothesis of randomness for both 3- and 4year horizon returns. However, his results based on simple autocorrelation test supported the mean reversion hypothesis at all horizons. 
Shiguang and Barnes (2001) used a simple serial correlation, runs and variance-ratio tests to test the weak-form efficiency hypothesis for both the Shenzhen and Shanghai Stock Markets. They use aggregate index and individual share data for daily, weekly, and monthly frequencies over the period from December 1990 to April 1998 for the Shanghai Stock Market and from April 1991 to April 1998 for the Shenzhen Stock Market. The findings rejected the week-form efficient market hypothesis for both the said China's markets

Parameswaran (2002) employed variance-ratio tests to testing the random walk hypothesis. Using weekly returns derived from daily returns for a period of 23 years, he found that eight out of ten size sorted portfolios do not follow a random walk. In addition, he also examined that non-trading is not a source of serial correlation in the large sized firms.

\section{Previous Empirical Studies of the Pakistani Stock Market}

Khilji (1993) examined the time-series properties of the Pakistani equity market. His study used monthly indices. He employed more than one method namely an errorcorrection model, first-order autoregressive model, and the Kalman Filter technique to investigate the dynamic fluctuations of monthly stock returns. He reported that the stock returns in Pakistan do not follow normal distribution. The distribution of stock returns is generally positively skewed and leptokurtic. The findings also pointed out the linear dependence for some indices. In addition, he found that the expected stock returns are constant and equal to long-term expected monthly returns. However, as reported by the author, these results are surprising for a developing economy and there are needs to further investigate the behavior of stock returns in Pakistan by using weekly or daily stock returns.

Jun and Uppal (1994) employed a simple autocorrelation test to analyze the time varying aspects of the Karachi Stock Exchange. The study used the monthly IFC indices as well as monthly share prices for 20 companies. They reported that the autocorrelation coefficients are statistically significant at 5 percent level for indices. In contrast, the estimated test statistics do not provide any rejection of the independence hypothesis for 17 out of the 20 individual stocks. Therefore, the authors concluded that there is, generally, no serial dependence in the Pakistani market.

Khilji (1994) explored the nature of equity returns in Pakistan. He conducted BDS methodology, developed by Brock, Dechert, and Scheinkman on both returns derived from weekly indices and residuals from an autoregressive model. He reported a strong non-linear dependence in six out of the eleven indices. Moreover, the author suggested the use of non-linear stochastic models like 'GARCH' to estimate the returns.

Husain (1997) employed the simple serial correlation test and Ljung-Box Q-statistic to test the independence hypothesis as well as he examined the distribution of stock returns through frequency distribution. He used daily data adjusted for volumes, 
dividend (cash and stock), and rights issues, for the general market index, 8 sector indices, and 36 individual stocks for the period January 1, 1989 to December 30, 1993. He concluded that the Pakistani equity market does not follow random walk. The study results provided evidence of the presence of strong serial dependence in stock returns and indicated the slow adjustment of the market to new information. Finally, he has claimed that the equity returns in Pakistani stock market cannot be characterized by the normal distribution.

Husain (1998) investigated the Ramadhan effect in the Pakistani equity market. The study covers the period from January 1, 1989 to December 30, 1993. His results based on GARCH model provided evidence that there is a significant decline in stock returns volatility is this month, however, the mean return indicated no statistically significant change ${ }^{2}$.

\section{The Random Walk Hypothesis (RWH)}

There are two fundamental implications of the random walk model:

1. Expected future returns are unpredictable in both short and long spans.

2. The variance of a sample is proportional to the sampling interval.

The testing of first hypothesis implies that the successive values of a time series are uncorrelated $^{3}$. It means the series has a unit root. Thus, the information about historical changes of a time series is ineffective for prediction of future changes. This hypothesis has parallel importance for both investors and policymakers. As a series does not follow random walk then an investor may increase the expected returns by using a historical piece of evidence.

${ }^{2}$ The literature reviewed clearly shows that there is conflicting evidence on the issue of stock prices behavior in Pakistan. Therefore, this issue needs further investigation. This study differs from those studies that examine the behavior of Pakistani stock market in a number of ways: First, it employs most recent financial data. Previous studies employed data for the period when Pakistani stock markets were underdeveloped (lack breath and depth). Second, this study employs the Lo-Mackinlay (1988) varianceratio test separately under homoscedasticity and heteroscedasticity, which also reports the weighted sum of the first $q-1$ autocorrelation coefficients, and thus provides more robust results than fundamental tests of Random Walk Hypothesis. Third, Pakistan conducted nuclear tests on May 28, 1998. The stock market behavior might have been affected due to this structural change. Therefore, this study tests the random hypothesis for pre-tests periods and after tests periods separately.

${ }^{3}$ If the returns of two stocks, $X$ and $Y$, are independent, but $Y$-stock trades less frequently than $X$-stock, then the price of $X$-stock will respond more quickly when news affecting both stocks arrives, as a consequence, the return on Y-stock will appear to respond with some lag to the return on $X$-stock, i.e., there will be cross-correlation between the returns on $X$-stock and $Y$-stock. 
This hypothesis has been extensively tested in a number of ways. Examples include significance of parameters in a returns prediction model (for instance, a Q-test from an AR(k) model), technical analysis (see, for example, Neftci (1990) or Bessembinder and Chan (1995), filter rules (examples include Fama and Blume (1966) and Grier and Albin (1973), or through the serial correlation test (see for details, Husain (1997)) $)^{4}$.

Second hypothesis deals with testing the variance of a time series' return is linear in the observation interval. It means the increments are uncorrelated. This hypothesis also has been tested severely. The first major among these is Lo \& Mackinlay (1988). They investigated, based on Hausman (1978) results, that the sampling distributions of variance rations over different sampling intervals and develop a test statistic based on this idea. The other studies including Peterba \& Summers (1988), Richardson \& Smith (1994), and Pan, Chiou, Hocking \& Rim (1991) have also been tested this hypothesis.

This hypothesis has also several important implications for investors and researchers. It is very important, for an investor, to explore the risk of investment in securities. An investor has interest to know the possibility of profits and losses. Furthermore, it provides information about the pattern of returns. However, some earlier studies have claimed that the pattern of returns is as normal distribution (see, for example, Errunza and Losq (1985)). On the other hand, some studies have reported that returns distribution is leptokurtic (see, for instance, Hsieh (1988), and Contingency Analysis (1997)). A leptokurtic distribution's tails are slimmer or longer with a higher peak relative to a normal distribution.

This study focuses on testing second hypothesis for the Pakistani stock market. This is not only because there are some important departure from the random walk that unit root test cannot detect, also because the autocorrelation aspect may yield interesting implications for alternative models of stock prices. For this purpose, the Lo and Mackinlay's variance-ratio tests are employed.

${ }^{4}$ However, these tests have several drawbacks that are given below:

1. Do not consider heteroscedasticity.

2. Do not have a standard normal distribution (asymptotically).

3. Do not report the average level of autocorrelation. 


\section{Testing Methodology}

The random walk null hypothesis suggests that the variance of a sample is linearly associated with sampling interval. Hence, the variance of the q-period return must be equal to the q times the variance of the one-period return:

$$
\frac{\operatorname{Var}\left(S R_{t}^{q}\right)}{q \times \operatorname{Var}\left(S R_{t}\right)}=1
$$

where $\mathrm{q}$ is any integer greater than one. The alternative hypothesis will be the ratio of the variance of the q-period return to the variance of the 1-period return divided by q is not equal to $1^{5}$. To explain the variance-ratio test, let $S P_{t}$ be the natural log of a stock price at time t (i.e., $S P_{t} \equiv \operatorname{In}\left(P_{t}\right)$, where $P_{t}$ is a stock price). A simple recursive relation as:

$$
S P_{r}=\alpha+S P_{r-1}+\xi_{1}
$$

where $\alpha$ is an arbitrary drift parameter and $\xi$, is the random disturbance term. Suppose that $2 n+1$ observation $\mathrm{SP}_{0}, \mathrm{SP}_{1}, \ldots, \mathrm{SP}_{2} \mathrm{n}$ of $\mathrm{SP}$ at equally spaced intervals are obtained and consider the following estimators for the unknown parameters $\mathrm{u}$ and $\delta_{0}^{2}$ :

$$
\begin{aligned}
& \hat{U} \equiv \frac{1}{2 n} \sum_{k=1}^{2 n}\left(S P_{k}-S P_{K-1}\right)=\frac{1}{2 n}\left(S P_{2 n}-S P_{0}\right) \\
& \hat{\delta}_{\alpha}^{2} \equiv 2 \frac{1}{n} \sum_{k=1}^{2 n}\left(S P_{k}-S P_{k-1}-\hat{U}\right)^{2} \\
& \hat{\delta}_{b}^{2} \equiv 2 \frac{1}{n} \sum_{k=1}^{n}\left(S P_{2 k}-S P_{2 k-1}-2 \hat{U}\right)^{2}
\end{aligned}
$$

The variance of $\hat{\delta}_{b}^{2}$ is based on the differences of every other observation; alternative variance estimators may be defined by using the differences of every qth observation. Let us suppose the nq+1 observation $\mathrm{SP}_{\mathrm{o}}, \mathrm{SP}_{1}, \ldots, \mathrm{SPnq}$, where $\mathrm{q}$ is any integral greater than 1. Define the estimators:

$$
\begin{aligned}
\hat{U} & \equiv \frac{1}{n q} \sum_{k=1}^{n q}\left(S P_{k}-S P_{k-1}\right)=\frac{1}{n q}\left(S P_{n q}-S P_{0}\right) \\
\hat{\delta}_{a}^{2} & \equiv \frac{1}{n q} \sum_{k=1}^{n q}\left(S P_{k}-S P_{k-1}-\hat{U}\right)^{2} \\
\hat{\delta}_{b}^{2}(q) & \equiv \frac{1}{n q} \sum_{k=1}^{n}\left(S P_{q k}-S P_{q k-q}-q \hat{U}\right)^{2}
\end{aligned}
$$

${ }^{5}$ While this variance-ratio would be exactly equal to one only under homoscedasticity, it still approaches one under the specification of the heteroscedasticity in Lo \& Mackinlay (1988). 
On the base of equation (6-8), a more convenient test statistic is given as, which is called ratio of variance and denoted by $\mathrm{J}_{\mathrm{d}}$ :

$$
J_{d}(q)=\frac{\hat{\delta}_{b}^{2}(q)}{\hat{\delta}_{a}^{2}}-1
$$

Under the finite-sample properties, the $J_{d}(q)$ test will convert in more powerful test:

where

$$
M_{r}(q)=\frac{\hat{\delta}_{c}^{2}(q)}{\hat{\delta}_{a}^{2}}-1
$$

$$
\hat{\delta}_{c}^{2}(q) \equiv \frac{1}{n q^{2}} \sum_{k=q}^{n q}\left(S P_{k}-S P_{k-q}-q \hat{U}\right)^{2}
$$

This differs from the estimator $\hat{\delta}_{b}^{2}(q)$ since this sum contains nq $-\mathrm{q}+1$ term, whereas the estimator $\hat{\delta}_{b}^{2}(q)$ contains on $\mathrm{n}$ terms. Finally, by using the unbiased variance estimators, the M-statistic as define ${ }^{6}$ :

$$
\bar{M}_{r}(q)=\frac{\bar{\delta}_{c}^{2}(q)}{\bar{\delta}_{a}^{2}}-1
$$

where

$$
\begin{gathered}
\bar{\delta}_{a}^{2} \equiv \frac{1}{n q-1} \sum_{k=1}^{n q}\left(S P_{k}-S P_{k-1}-\hat{U}\right)^{2} \\
\bar{\delta}_{c}^{2}(q) \equiv \frac{1}{m} \sum_{k=q}^{n q}\left(S P_{k}-S P_{k-q}-q \hat{U}\right)^{2} \\
m=q(n q-q+1)\left(1-\frac{q}{n q}\right)
\end{gathered}
$$

For an aggregate value $\mathrm{q}$ of 2 , the $\bar{M}_{r}(q)$ can expand as

$$
\bar{M} \cdot(q)=\hat{\rho}(1)-\frac{1}{4 n \hat{\delta}_{c}^{2}}\left\{\left(S P_{1}-S P_{0}-\hat{U}\right)^{2}+\left(S P_{2 n}-S P_{2 n-1}-\hat{U}\right)^{2}\right\} \cong \hat{\rho}(1)
$$

${ }^{6} \bar{M}_{r}(q)+1=\frac{\bar{\delta}_{r}^{2}(q)}{\bar{\delta}_{a}^{2}}$ is called variance-ratio and generally denoted by $\operatorname{VR}(q)$. 


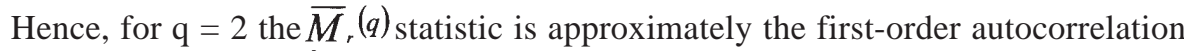
coefficient estimator $\hat{\rho}(1)$ of the differences. More generally, it may be shown that:

$$
\bar{M}_{r}(q) \cong \frac{2(q-1)}{q} \hat{\rho}(1)+\frac{2(q-2)}{q} \hat{\rho}(2)+\Lambda+\frac{2}{q} \hat{\rho}(q-1)
$$

where $\hat{\rho}(k)$ is the $\mathrm{K}^{\text {th }}$ order autocorrelation coefficient estimator of the first differences of $\mathrm{SPt}^{7}$. Hence, the variance-ratio can be written in terms of the autocorrelation function (ACF) for the returns - it is simply a declining weighted sum of the first $q-1$ autocorrelation coefficient estimators of the first differences (returns).

\section{Testing the Random Walk Hypothesis}

The null and alternative hypotheses are defined as:

$$
\begin{array}{ll}
\mathrm{H}_{0}: & \frac{\bar{\delta}_{c}^{2}(q)}{\bar{\delta}_{a}^{2}}=1 \quad \text { (series follow random walk) } \\
\mathrm{H}_{\mathrm{a}}: & \frac{\bar{\delta}_{c}^{2}(q)}{\bar{\delta}_{a}^{2}} \neq 1 \quad \text { (series does not follow random walk) }
\end{array}
$$

After deriving an asymptotic distribution of the variance ratios, two alternative statistics are derived to test the null hypothesis for different specifications of error term behavior.

\section{a. The Homoscedastic Standard Normal Test-Statistic, Z(q)}

This test statistic considers an independent and identical distributed normal error term. Therefore, the standard normal test statistic for homoscedastic increments is computed as follows:

$$
Z(q)=\frac{\bar{M}_{r}(q)}{\{\eta(q)\}^{1 / 2}} \approx N(0,1)
$$

where $\eta(q)$ is the asymptotic variance of variance-ratio under homoscedasticity, defined as:

$$
\eta(q)=\frac{2(2 q-1)(q-1)}{3 q(n q)}
$$

\footnotetext{
${ }^{7}$ However, the Box-Pierce Q-statistic is a linear combination of squared autocorrelations with all the weights set identically equal to unity.
} 


\section{b. The Heteroscedastic Standard Normal Test-Statistic, Z*(q)}

A rejection of the Random Walk Hypothesis because of heteroscedasticity would not be of much interest. Hence, to avoid this, the heteroscedasticity-consistent standard normal test statistic is employed, which relaxed the assumption of normality. The heteroscedasticity-robust test statistic is defined as follows:

$$
Z^{*}(q)=\bar{M},(q) / \sqrt{\hat{\theta}(q)} \approx N(0,1)
$$

where $\hat{\theta}(q)$ is the heteroscedasticity-consistent asymptotic variance of the variance ratio:

$$
\hat{\theta}(q)=\sum_{j=1}^{q-1}\left[\frac{2(q-j)}{q}\right]^{2} \hat{\vartheta}(j)
$$

where

$$
\hat{\vartheta}(j)=\frac{\sum_{k=j+1}^{n q}\left(X_{k}-X_{k-1}-\hat{U}\right)^{2}\left(X_{k-j}-X_{k-j-1}-\hat{U}\right)^{2}}{\left[\sum_{k=1}^{n q}\left(X_{k}-X_{k-1}-\hat{U}\right)\right]^{2}}
$$

This study used both the homoscedasticity test statistic, $Z(q)$ and heteroscedasticityrobust test statistic, $Z^{*}(q)$ to test the behavior of stock prices ${ }^{8}$.

\section{The Data}

To test the random walk in stock market prices, the study uses the KSE-100 index over the 450-week time span from January 1, 1995 to December 30, 2004. The weekly stock returns are derived from daily stock prices. The weekly returns are computed as the return from Wednesday's closing prices to the following Wednesday's close. If the following Wednesday's price is missing, then Thursday's price is used. If Thursday's price is missing, the return for that week is reported as missing. The date is obtained from the Vital Information Services (ViS) databases.

\footnotetext{
${ }^{8}$ If the Random Walk Hypothesis is rejected under homoscedasticity and is accepted under heteroscedasticity then one can say the series does not follow random walk due to heteroscedasticity. In contrast, if the rejection of the Random Walk Hypothesis is consistent under homoscedasticity and heteroscedasticity tests statistic, then the series does not follow random walk due to autocorrelations of increments.
} 


\section{Empirical Results and Analyses}

Using 1-week as our base observation interval, the Random Walk Hypothesis is tested by calculating the variance-ratio $1+\bar{M}_{r}(q), \eta(q)$, and $\mathrm{Z}(\mathrm{q})$ for each of the cases $\mathrm{q}=2$, 4, 8 and 16. In addition, the heteroscedasticity-consistent variance-ratio test is also performed by calculating the $1+\bar{M}_{r}(q), \hat{\theta}(q)$, and $\mathrm{Z}^{*}(\mathrm{q})$ for each of the cases $\mathrm{q}=2,4$, 8 and 16.

The actual variance ratios $1+\bar{M}_{r}(q)$ are reported in main rows and the variance-ratio tests, Z(q) and $Z^{*}(\mathrm{q})$ statistics are given in parentheses in Table 1a and 1b, respectively. In Table 1a, the first row presents the variance-ratios and tests statistics for the entire 384-week sample period, and the next two rows give the results for two subperiods from January 1, 1995 to May 27, 1998 with a total of 174 weekly observation, and from May 28, 1998 to December 30, 2004 with a total of 276 weekly observation.

Table 1a reveals that under the maintained hypothesis of homoscedasticity, there is evidence rejecting the Random Walk Hypothesis at two values of $\mathrm{q}$ (when $\mathrm{q}=2$ and 4) out of the four values for the entire sample period. For example, the Z-statistics associated with intervals $q=2,4,8$ and 16 are $-3.25,-2.75,-1.03$ and -0.82 , respectively. Compared with the conventional critical value (which is 1.96 for the five percent level), two out of these four Z's indicate that the variance-ratio is significantly different from one at five per cent level. The Random Walk Hypothesis is therefore rejected for the market index for two out of the four interval lengths examined. Note that as shown in Lo and Mackinlay (1988), the variance-ratios associated with each q are not independent of each other. In fact, it is shown explicitly in Lo \& Mackinlay that the variance-ratio (for each q) minus one is approximately q-1 times the weighted sum of the first q-1 autocorrelation coefficients. Under this scenario, the probability of rejection when one of the four statistics is large and three of them are small (as in the case of the market index with entire sample) is not as high as when all four statistics are larger.

The estimates of the variance ratio are less than 1 for all cases (i.e., the variance ratios associated with the value $\mathrm{q}$ of $2,4,8$ and 16 are $0.89,0.850 .84$ and 0.82 respectively). It implies that there is a negative serial correlation in stock returns ${ }^{9}$. However, the serial correlation is both statistically and economically insignificant and provides little evidence against the random walk hypothesis. For example, the largest average Z(q) statistic for market index over the entire sample occurs for $q=2$ is -3.25 With a serial correlation of 11 percent; the smallest average $\mathrm{Z}(\mathrm{q})$ is -0.82 with a serial correlation of -18 percent. Market index over the entire sample occurs for $q=2$ is -3.25 with a serial correlation of 11 percent; the smallest average $\mathrm{Z}(\mathrm{q})$ is -0.82 with a serial correlation of -18 percent.

${ }^{9}$ The serial correlation is -11 percent, -15 percent, -16 percent, and -18 percent when $q=2,4,8$ and 16 respectively. 
As Table 1a indicates that the rejection of the Random Walk Hypothesis does not occur for the first sub-period, therefore, the Pakistan Stock Market follows random walk over the period from January 1, 1995 to May 27, 1998. However, quite opposed the case of the entire sample the average variance ratio for three values $q(q=2,4$ and 16) out of the four are larger than 1 . It means there is positive autocorrelation in stock returns except when $\mathrm{q}=4$.

The random walk null hypothesis is rejected for the period May 28, 1998 to December 30,2004 when $q=2$ and 4, however, the null hypothesis is accepted when $q=8$ and 16. Furthermore, we find there is a negative serial correlation of weekly stock return over this period.

\section{Table 1a}

\section{Estimates of Variance-Ratios VR(q) \& Variance-Ratio Test Statistics Z(q)}

Variance-ratio test of the random walk hypothesis for weekly KSE-100 index, for the entire sample period from January 1, 1995, to December 30, 2004, and for two subperiods from January 1, 1995, to May 27, 1998, and from May 28, 1998, to December 30, 2004. One-week is taken as a base observation interval. The variance ratios $1+\bar{M}_{r}(q)$ are reported in the main rows, with the homoscedasticity test statistic Z(q) given in parentheses immediately below each main row. Under the random walk null hypothesis the value of the variance ratio is 1 and the test statistics have a standard normal distribution (asymptotically). Test statistics marked with one asterisk and with two asterisks indicate that the corresponding variance ratios are statistically different from 1 at the one per cent and 5 percent levels of significance, respectively.

\begin{tabular}{|l|c|c|c|c|c|}
\hline & \multirow{2}{*}{$\begin{array}{c}\text { Number } \\
\text { nq of base } \\
\text { observation }\end{array}$} & \multicolumn{4}{|c|}{$\begin{array}{c}\text { Number q of base observations aggregated to } \\
\text { form variance ratio }\end{array}$} \\
\cline { 3 - 6 } & \multirow{2}{*}{ Time period } & $\mathbf{2}$ & $\mathbf{4}$ & $\mathbf{8}$ & $\mathbf{1 6}$ \\
\hline 1-Jan-1995 to 30-Dec-2004 & 450 & $\begin{array}{c}0.89 \\
(-3.25)^{*}\end{array}$ & $\begin{array}{c}0.85 \\
(-2.75)^{*}\end{array}$ & $\begin{array}{c}0.84 \\
(-1.03)\end{array}$ & $\begin{array}{c}0.82 \\
(-0.82)\end{array}$ \\
\hline 1-Jan-1995 to 27-May-1998 & \multirow{2}{*}{174} & $\begin{array}{c}1.14 \\
(1.87)\end{array}$ & $\begin{array}{c}1.17 \\
(1.18)\end{array}$ & $\begin{array}{c}1.02 \\
(0.10)\end{array}$ & $\begin{array}{c}0.85 \\
(-0.45)\end{array}$ \\
\hline 28-May-1998 to 30-Dec-2004 & \multirow{2}{*}{276} & $\begin{array}{c}0.76 \\
(-3.48)^{*}\end{array}$ & $\begin{array}{c}0.64 \\
(-2.73)^{*}\end{array}$ & $\begin{array}{c}0.60 \\
(-1.89)\end{array}$ & $\begin{array}{c}0.63 \\
(-1.20)\end{array}$ \\
\hline
\end{tabular}


Since the results obtained from these Z(q)'s are under the maintained hypothesis of homoscedasticity, the rejections of the random walk may either be due to heteroscedasticity or to serial correlation. To investigate this issue, a heteroscedasticityrobust variance-ratio test statistic, $Z^{*}(\mathrm{q})$ is also performed. The test results, presented in Table 1b, point out that the Pakistani stock market at aggregate level follows random walk over the entire sample period as well as over both the sub-periods for all four interval lengths. This implies the variance-ratio is different from one, in the case of entire sample when $\mathrm{q}=2$ and in the case of sub-period from May 28, 1998, to December 30,2004 when $q=2$ and 4, due to heteroscedasticity rather than to autocorrelation. In other words, the random walk is rejected because of heteroscedasticity's presence in weekly stock price increments ${ }^{10}$.

\section{Table 1b}

\section{Estimates of Variance-Ratios VR(q) \& Heteroscedasticity-Robust Variance-Ratio Test Statistics Z*(q)}

Variance-ratio test of the Random Walk Hypothesis for weekly KSE-100 index, for the entire sample period from January 1, 1995, to December 30, 2002, and two sub-periods from January 1, 1995, to May 27, 1998, and from May 28, 1998, to December 30, 2004. One-week is taken as a base observation interval. The variance ratios $1+\bar{M}_{r}(q)$ are reported in the main rows, with the heteroscedasticity-robust test statistic $\mathrm{Z}^{*}(\mathrm{q})$ given in parentheses immediately below each main row. Under the random walk null hypothesis the value of the variance ratio is 1 and the test statistics have a standard normal distribution (asymptotically). Test statistics marked with one asterisks and with two asterisks indicate that the corresponding variance ratios are statistically different from 1 at the one percent and 5 percent levels of significance, respectively.

\begin{tabular}{|l|c|c|c|c|c|}
\hline & \multirow{2}{*}{$\begin{array}{c}\text { Number } \\
\text { nq of base } \\
\text { Time period }\end{array}$} & \multicolumn{4}{|c|}{$\begin{array}{c}\text { Number q of base observations aggregated to } \\
\text { form variance ratio }\end{array}$} \\
\cline { 3 - 6 } & \multirow{2}{*}{ observation } & $\mathbf{2}$ & $\mathbf{4}$ & $\mathbf{8}$ & $\mathbf{1 6}$ \\
\hline 1-Jan-1995 to 30-Dec-2002 & 450 & $\begin{array}{c}0.89 \\
(-0.61)\end{array}$ & $\begin{array}{c}0.85 \\
(-0.54)\end{array}$ & $\begin{array}{c}0.84 \\
(-0.46)\end{array}$ & $\begin{array}{c}0.82 \\
(-0.45)\end{array}$ \\
\hline 1-Jan-1995 to 27-May-1998 & \multirow{2}{*}{174} & $\begin{array}{c}1.14 \\
(1.69)\end{array}$ & $\begin{array}{c}1.17 \\
(1.09)\end{array}$ & $\begin{array}{c}1.02 \\
(0.10)\end{array}$ & $\begin{array}{c}0.85 \\
(-0.45)\end{array}$ \\
\hline 28-May-1998 to 30-Dec-2004 & \multirow{2}{*}{276} & $\begin{array}{c}0.76 \\
(-0.89)\end{array}$ & $\begin{array}{c}0.64 \\
(-0.87)\end{array}$ & $\begin{array}{c}0.60 \\
(-0.81)\end{array}$ & $\begin{array}{c}(-0.63 \\
\end{array}$ \\
& & & &
\end{tabular}

\footnotetext{
${ }^{10}$ Although all the results are based on nominal stock returns and nominal exchange rate series, it is apparent that almost the same results would obtain with real or excess returns. Since the volatility of weekly nominal returns is so much larger than that of the inflation and Treasury-bill rates, the use of nominal, real, or excess returns in a volatility test will yield practically identical implication.
} 


\section{Conclusion and Recommendations}

This study contributes to the growing literature on random walk in stock prices by testing the random walk hypothesis for the Pakistani equity market. The random walk hypothesis is tested by adopting a variance-ratio test developed by Lo \& Mackinlay (1988). The study uses weekly data for the KSE-100 index over the span from January 1, 1995 to December 30, 2004. The weekly stock returns are derived from daily corresponding returns. Furthermore, the same methodology is employed for the two subperiods from January 1, 1995 to May 27, 1998, and from May 28, 1998 to December 30, 2004.

The estimates of this study show that stock prices generally behave non-randomly under the assumption of homoscedasticity over the entire examined period. The same conclusion is drawn during the second sub-period. However, during the first subperiod, the null hypothesis of random is not rejected at common level of significance. The rejection of random walk model, although, is not robust to heteroscedasticity. It implies that the stock prices do not follow random walk due to changes in variances (heteroscedasticity) rather than to autocorrelation. The absence of a random walk in stock prices is implying that an investor can predict future movements of stock prices by using information about past price movements. Higher returns can necessarily be earned by using investment strategies based on past information of stock prices rather than investing in a portfolio consisting of randomly picked stocks

The negative serial correlation in stock returns implies that the stock prices in Pakistan overreact to insider as well as to outsider information. Therefore, the stock market falls back to normal after following the first dramatic reaction to a shock. This view is consistent with the permanent/transitory components model, which basically says that stock markets are driven by a fundamental component that reflects the efficient market prices and deviations from efficiency and this component reverts to something that is close to zero in the long-term.

\section{REFERENCES}

Bessembinder, H. \& K. Chan, 1992. "Time-Varying Risk Premia and Forecast able Returns in Future Markets", Journal of Financial Economics, Volume 32, Pages 169194.

Campbell, J. \& G. Mankiw, 1987. “Are Output Fluctuations Transitory?”, Quarterly Journal of Economics, Volume 102, Pages 857-880.

Cochrane. J., 1987b. "Spectral Density Estimates of Unit Roots?", Working Paper, University of Chicago. Contingency Analysis, 1997. Kurtosis (Leptokurtic and Platykurtic), http://www.CointegencyAnalysis.com/GlossaryKurtosis.htm

Errunza, V. \& E. Losq, 1985. "International Asset Pricing Under Mild Segmentation: Theory and Test", Journal of Finance, Volume 40, Pages 105-124. 
Fama, Eugene \& Kenneth French, 1988. "Permanent and Temporary Components of Stock Prices”, Journal of Political Economy, Volume 96, Pages 246-273.

Fama E.F. \& M.E. Blume, 1966. "Filter Rules and Stock Market Trading”, Journal of Business, Volume 39, Pages 226-241.

Fazal Husain, 1997. "The Random Walk Model in the Pakistani Equity Market: An Examination", The Pakistan Development Review, Volume 36, Number 3, Pages 221240

Fazal Husain, 1998. "A Seasonality in the Pakistani Equity Market: The Ramadhan Effect”, The Pakistan Development Review, Volume 37, Number 1, Pages 77-81.

Grier P C. \& P.S. Albin, 1973. "None-random Prices Changes in Association with Trading in Large Blocks", Journal of Business, Volume 46, Pages 425-433.

Hsieh David, 1988. "The Statistical Property of Daily Foreign Exchange Rates: 19741983”, Journal of International Economics, Volume 24, Pages 129-145.

Hulzinga, J., 1987, “An Empirical Investigation of the Long-term Behavior of Real Exchange Rate", Carnegie-Rochester Conference Series on Public Policy, Number 27.

Jun, K. \& Jamshed Uppal, 1994. "Portfolio Flows to Pakistan: Trends and Policies", A Paper presented at the Private Sector Development Conference, Lahore University of Management Sciences, Lahore.

Kim, M.J., Nelson, R.C. \& Startz, R., 1991. "Mean Reversion in Stock Prices? A Reappraisal of the Empirical Evidence", The Review of Economic Studies, Volume 58, Pages 515-528.

Khilji , N. 1993. "The Behavior of Stock Returns in Emerging Market: A Case Study of Pakistan", The Pakistan Development Review, Volume 32, Number 4, Pages 593 604.

Khilji, N. 1994. "Non-linear Dynamics and Chaos: Application to Financial Markets in Pakistan", The Pakistan Development Review, Volume 33, Number 4, Pages 14171429.

Laurence, M., 1986. "Weak Form Efficiency in the Kuala Lumpur and Singapore Stock Markets", Journal of Banking and Finance, Volume 10, Pages 431-445.

Leroy, S.F., 1973. "Risk Aversion and the Martingale Property of Stock Returns", International Economic Review, Volume 14, Pages 436-446. 
Lo, A.W. \& A. Craig Mackinlay, 1988. "Stock Prices do not Follow Random Walks: Evidence from A Simple Specification Test", Review of Financial Studies, Volume 1, Pages 41-66.

Lo, A.W. \& A. Craig Mackinlay, 1989. "The Size and Power of the Variance-ratio Test in Finite Samples: A Monte Carlo Investigation", Journal of Econometrics, Volume 40, Pages 203-238.

Lucas, R.E., 1978. “Asset Prices in Exchange Economy”, Econometrica, Volume 46, Pages 1429-1446.

Neftci, Salih and Policano, Andrew, 1990. "On Some Sample Path Properties of Intraday Futures Prices", Review of Economics and Statistics, Volume 72, Issue 3, Pages 529-536.

Ole Risager, 1998. "Random Walk or Mean Reversion: The Danish Stock Market since World War 1", Institute for Nationalokonomi, Working paper Number 7.

Parameswaran, S.K., 2000. "A Method of Moments Test of the Random Walk Model in the Presence of Bid-ask Spreads and Non-synchronous", Applied Finance, Volume 6, Number 1, Pages 1-22.

Pan, M.S., Chiou, J.R., Hocking, R. \& Rim, H.K., 1991. “An Examination of MeanReverting Behavior of Stock Prices in Pacific-Basin Stock Markets", Pacific-Basin Capital Market Research, Volume 2, Pages 333-342.

Poterba, J.M. \& L.H. Summers, 1988. "Mean Reversion in Stock Prices-Evidence and Implications", Journal of Financial Economics, Volume 22, Pages 27-59.

Natividad Blasco, Cristina Del Rio \& Rafael Santamaria., 1997. "The Random Walk Hypothesis in the Spanish Stock Market: 1980-1992”, Journal of Business Finance and Accounting, Volume 24, Number 5, Page 667.

Richardson and Smith, 1994. “A Unified Approach to Testing for Serial Correlation in Stock Returns", Journal of Business, Pages 371-399.

Samuelson P.A., 1965. "Proof that Properly Anticipated Prices Fluctuate Randomly", Industrial Management Review, Volume 6, Pages 41-49.

Shiguang Ma \& Michelle L. Barnes, 2001. “Are China’s Stock Markets Really Weak Form Efficient?", Center for International Economic Studies, Discussion Paper No. 0119. 